\title{
A Hybrid Nine-Arm Modular Multilevel Converter for Medium-Voltage Six-Phase Machine Drives
}

\author{
Mohamed S. Diab, Student Member, IEEE, Ahmed A. Elserougi, Senior Member, IEEE, \\ Ahmed M. Massoud, Senior Member, IEEE, Shehab Ahmed, Senior Member, IEEE, \\ and Barry W. Williams
}

\begin{abstract}
The nine-arm modular multilevel converter (9A-MMC) has been recently proposed as a reduced MMC topology variation for six-phase drive applications, with $25 \%$ reduction in the number of employed arms and associated components, compared to a standard dual three-phase MMC, however with a limited output voltage amplitude. This paper proposes a hybrid 9A-MMC comprised of half-bridge submodules (SMs) in both the upper and lower arms, and full-bridge SMs in the middle arms. By employing the negative-voltage state of the fullbridge SMs, the hybrid 9A-MMC avoids the limitations imposed on the dc-link voltage utilization, while achieving further reduction in the component count, compared to a standard 9A-MMC with identical half-bridge SMs. The operating principles of the proposed hybrid 9A-MMC are illustrated with mathematical analysis, while its characteristics are verified through both simulation and experimentation. An assessment of the proposed topology quantifying its employed components is also provided, in comparison to other MMC-based six-phase machine drives.
\end{abstract}

Index Terms-Hybrid modular multilevel converter (MMC), medium-voltage machine drive, nine-arm MMC, six-phase machines.

Manuscript received May 24, 2018; revised August 23, 2018 and October 13, 2018; accepted October 24, 2018. (Corresponding author: Mohamed S. Diab)

M. S. Diab is with the Department of Electronic and Electrical Engineering, University of Strathclyde, Glasgow G1 $1 \mathrm{XQ}$, U.K., and also with the Electrical Engineering Department, Faculty of Engineering, Alexandria University, Alexandria 21544, Egypt (e-mail: mohamed.diab@strath.ac.uk).

A. A. Elserougi is with the Electrical Engineering Department, Faculty of Engineering, Alexandria University, Alexandria 21544, Egypt (e-mail: ahmed.elserougi@alexu.edu.eg)

A. M. Massoud is with the Department of Electrical Engineering, Qatar University, Doha 2713, Qatar (e-mail: ahmed.massoud @qu.edu.qa).

S. Ahmed is with the Department of Electrical Engineering, King Abdullah University of Science and Technology, Thuwal 23955-6900, Saudi Arabia (e-mail: shehab.ahmed@kaust.edu.sa).

B. W. Williams is with the Department of Electronic and Electrical Engineering, University of Strathclyde, Glasgow G1 1XQ, U.K. (e-mail: barry.williams@strath.ac.uk).

\section{INTRODUCTION}

$\mathrm{W}$ ITH the wide deployment of high-power applications in various industry sectors, including both rotary and traction areas, the power level requirement of the adjustablespeed drives is increasing to scores of megawatts, triggering the need for high-power driving at the medium-voltage (MV) level [1]. Over the past decades, the development of MV machine drives has been an active research area, where different MV converter topologies have found their application in the market [2]-[3]. Among them, the multilevel converter topologies have established themselves as a mature technology which has been favored by MV drives manufacturers, being able to provide a stepped output voltage waveform that reduces the $d v / d t$ stresses at the motor terminals. However, with the state-of-the-art multilevel converter topologies experiencing challenging shortcomings, the modular multilevel converter (MMC) has robustly found its way as a promising competitor for medium- to high-voltage high-power applications, outperforming its counterparts [4]. Being in the multilevel category, the MMC inherits the advantages of the state-of-the-art multilevel converter topologies, while solely enjoying the features of modularity, scalability, redundancy, and reliability [5]. These advantages promoted the MMC to be the next generation machine-drive technology, where it has been addressed, in this regard, within numerous diversified studies [6]-[9].

Over the time, three-phase machines have been adopted as a standard choice for motor drives realization. Nonetheless, in the last few decades, multiphase machines have reemerged as a potential alternative for various industrial applications, motivated by the advancement in power electronics, which facilitates synthesizing any number of phase voltages [10]. Multiphase machines have unique advantages over their threephase counterparts, that can briefly be highlighted in the fault tolerance, high power density, reduced torque ripple and perphase stator current, and lower dc-link current harmonic of the multiphase drive system. Consequently, multiphase drives are progressively breaking the technical barriers, finding a place in applications where reliability and fault tolerance are a prime concern [11]-[13].

Being the most applicable winding arrangement, six-phase machines, with either symmetrical or asymmetrical winding 


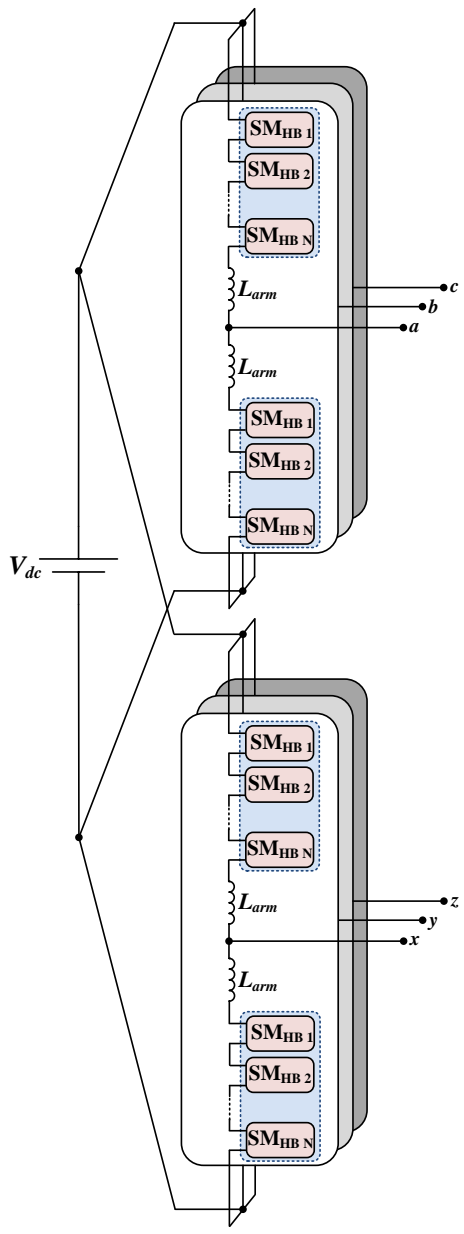

(a)

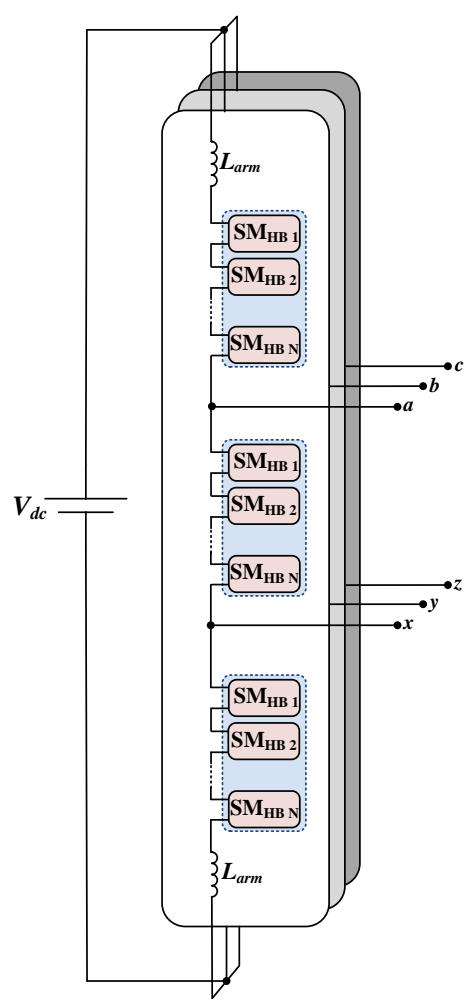

(b)

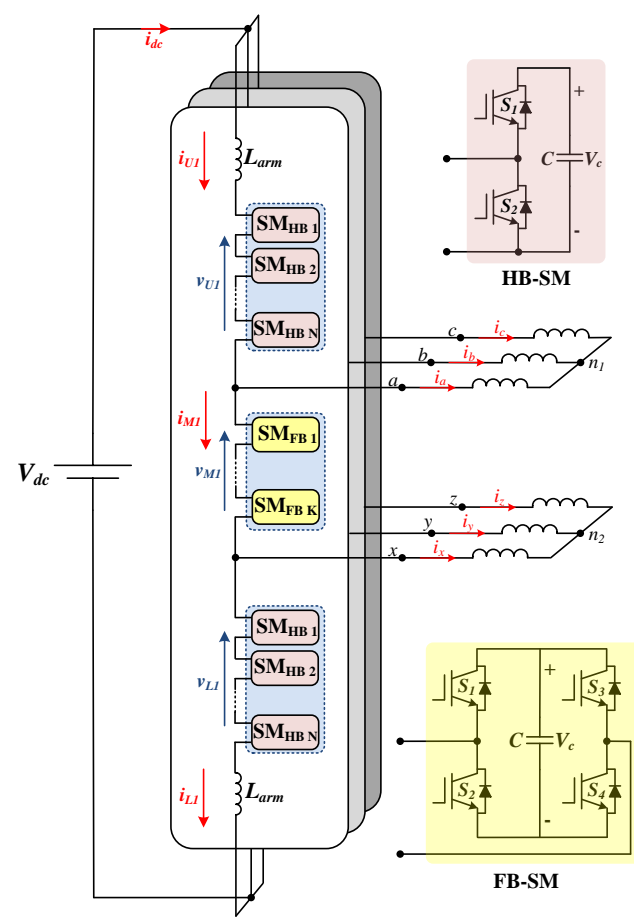

(c)

Fig. 1 Six-phase machine drive using (a) a 12A-MMC (b) a 9A-MMC and (c) a hybrid 9A-MMC.

layouts, have been the focus of attention among the numerous multiphase possibilities. The specific attraction of six-phase machines versus other possible alternatives typically returns to their ready adaptation with standard three-phase converter topologies. Through an enriched body of literature, six-phase machines have been studied with different aspects pertinent to their modeling, control, and applications [14]-[19].

With the dual three-phase inverter is the off-the-shelf drive topology for six-phase machines, dual three-phase MMC has been applied to drive both asymmetrical and symmetrical MV six-phase machines in [20] and [21], respectively. Nonetheless, the increased number of inverter legs and employed IGBTs fostered the need for topology variation to fulfill the requirements in a more economic and efficient way. That is, a reduced MMC structure, denoted as the nine-arm MMC (9A-MMC), has been recently adopted as an MV sixphase machine drive with $25 \%$ reduction in both silicon area and reactive elements [22]-[24]. However, as with most reduced component-count topologies, performance tradeoff was unavoidable where limitations were imposed on the utilization of the dc-link voltage supplying the 9A-MMC. That is, the dc-link voltage is increased by $50 \%$ to achieve the same level of power delivery, which counter-balances the scored merits.

To eliminate the imposed restriction of the attainable voltage amplitude, this paper proposes a hybrid design of the 9A-
MMC, which achieves the same performance as the dual three-phase MMC, while employing at most the same number of IGBTs and a lower number of submodule (SM) capacitors, compared to a traditional 9A-MMC. The proposed hybrid 9AMMC combines half-bridge submodules (HB-SMs) in both the upper and lower arms, and full-bridge submodules (FBSMs) only in the middle arms. That is, the modulation index of the 9A-MMC is promoted by employing the FB-SM's negative-voltage state which enhances the dc-link voltage utilization without any further compromise [25].

\section{MMC-BASEd SiX-Phase Machine DRIVES}

The traditional approach to drive a six-phase machine using the MMC topology is to employ a dual three-phase MMC, as shown in Fig. 1a, to generate two sets of three-phase voltages electrically shifted by $30^{\circ}$ or $60^{\circ}$ for either asymmetrical- or symmetrical-winding machines, respectively. The dual threephase MMC incorporates six phase-legs each composed of two arms connected in series through arm inductor, $L_{\text {arm }}$. Each arm is formed by $N$ series connected SMs. The SM is commonly an $\mathrm{HB}$ cell employing a dc capacitor of an equivalent capacitance $C$ and a nominal voltage $V_{c}$. Since the dual three-phase MMC employs twelve arms, it is denoted hereafter as the twelve-arm MMC (12A-MMC).

With the increased number of IGBTs and SM capacitors employed by the 12A-MMC, a 9A-MMC has been presented 
as a topology variation with a reduced structure that alleviates the size of the six-phase machine drive. As the name implies, the 9A-MMC employs nine arms evenly assorted in three legs each formed by upper, middle, and lower arms, all employing HB-SMs. The six-phase load terminals are realized through the intermediary points between each two series connected arms, as shown in Fig. 1b. The 25\% reduction in the number of arms, compared to the 12A-MMC, arises from the fact that the $9 \mathrm{~A}-\mathrm{MMC}$ is a direct consequence of integrating two threephase MMCs, with dual function middle arms. The 9A-MMC is intrinsically inspired from the nine-switch voltage-source inverter which has been firstly evolved to supply two independent three-phase machines [26], while recently has been adopted as a six-phase machine drive [19].

The utilization of the 9A-MMC reduces the number of employed IGBTs and their accessories in addition to both arm inductors and SM capacitors and their measuring transducers, which eventually reduces the system size, complexity, and cost. Notwithstanding, similar to the nine-switch inverter, the 9A-MMC experiences limited voltage amplitude, where the utilization of the dc-link voltage, $V_{d c}$, is reduced to $1 / 3$, compared to the 12A-MMC. That is, the voltage across any of the upper, middle, and lower arms ranges between 0 and $2 / 3 V_{d c}$, where the SM capacitor voltage, of all arms, is reduced to $2 V_{d c} / 3 N$. This operational limit arises due to the dual functionality of the middle arms, which necessitates increasing the dc-link voltage by $50 \%$ to deliver the same amount of power as the 12A-MMC.

\section{HYBRID NINE-ARM MMC}

To promote the dc-link voltage utilization of the 9A-MMC, with further reduction in topology components, this paper proposes a hybrid 9A-MMC which inherits the typical structure of the standard 9A-MMC, however, incorporates mixed SM cells. The hybrid 9A-MMC is shown in Fig. 1c, feeding a six-phase machine with isolated neutral points. Both the upper and lower arms are formed by $N$ series connected HB-SMs, while the middle arm is composed by $K$ series connected FB-SMs. The value of $K$ is determined as a portion of $N$, depending on the phase shift between the two sets of three-phase output voltages.

\section{A. Arm Voltages}

Referring to Fig. 1c, a general form for the two three-phase voltage sets are:

$$
\begin{aligned}
& v_{j n_{1}}=V_{o} \cos \left(\omega t-\frac{2 \pi}{3} m\right), m=0,1,2 \text { for } j=a, b, c \\
& v_{j n_{2}}=V_{o} \cos \left(\omega t-\frac{2 \pi}{3} m+\emptyset\right), m=0,1,2 \text { for } j=x, y, z
\end{aligned}
$$

where $\omega$ is the output angular frequency, $\varnothing$ is the phase angle between the two voltage sets, and $V_{o}$ is the magnitude of the output phase-voltage, and is defined as same as the voltage magnitude of traditional 12A-MMC as follows.

$$
V_{o}=\frac{1}{2} M V_{d c}
$$

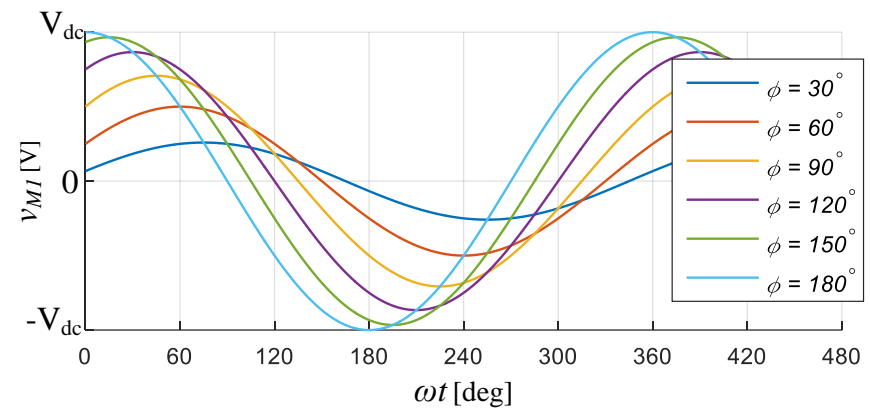

Fig. 2 Middle-arm voltage variation relative to the phase-shift angle ( $M$ $=1$ ).

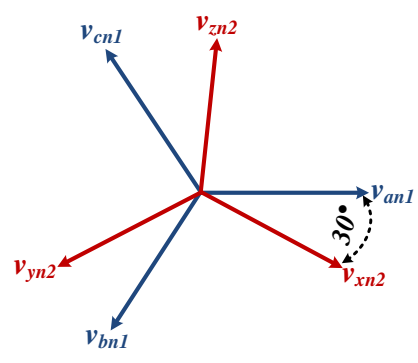

(a)

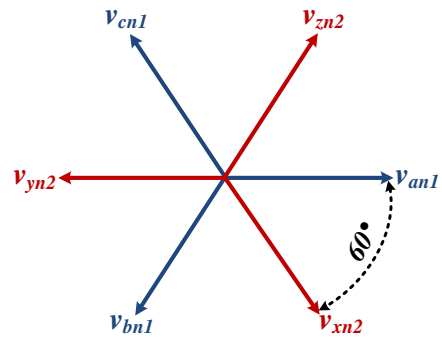

(b)
Fig. $3 \mathrm{~A}$ vector diagram for the six-phase voltages required by (a) asymmetrical machine and (b) symmetrical machine.

where $M$ is the modulation index, ranging from 0 to 1 , while $V_{d c}$ is the input dc voltage. Accordingly, both the upper and lower arms are controlled to generate a unidirectional voltage ranging from 0 to $M V_{d c}$. Considering leg-1 of the hybrid 9AMMC, which provides the machine phase-terminals $a$ and $x$, the voltage across both the upper and lower arms are given as shown in (3), where the subscripts $U$ and $L$ are utilized to denote the upper and lower arm, respectively, while the subscript $M$ is utilized hereafter to refer to the middle arm.

$$
\begin{gathered}
v_{U 1}=\frac{1}{2} V_{d c}[1-M \cos (\omega t)] \\
v_{L 1}=\frac{1}{2} V_{d c}[1+M \cos (\omega t+\emptyset)]
\end{gathered}
$$

The voltage balance between the dc-link voltage and the hybrid 9A-MMC legs implies the middle-arm voltage be bidirectional, as follows.

$$
\begin{gathered}
v_{M 1}=V_{d c}-v_{U 1}-v_{L 1} \\
=\frac{1}{2} M V_{d c} \sqrt{2(1-\cos \emptyset)} \cos (\omega t+\alpha) \\
\alpha=\tan ^{-1} \frac{\sin \emptyset}{\cos \emptyset-1}
\end{gathered}
$$

As demonstrated by (4), the magnitude of the middle-arm voltage depends on the phase angle $\emptyset$, which is graphically demonstrated in Fig. 2 for different values of $\emptyset$, at unity modulation index. It can be shown that, unlike both the upperand lower-arm voltages, the middle-arm voltage is comprised only of an ac component with a magnitude that is directly proportional to the angle $\emptyset$, with a maximum swing of $\pm V_{d c}$. The bidirectional middle-arm voltage can only be realized through the incorporation of FB-SMs in the middle arm, where the number of employed FB-SMs is determined 
according to the angle $\emptyset$. Since the hybrid 9A-MMC is ultimately proposed as a six-phase machine drive, the angle $\varnothing$ will be either $30^{\circ}$ or $60^{\circ}$ depending on whether the machine has an asymmetrical or symmetrical winding layout, respectively, as vectorially represented in Fig. 3. That is, the magnitude of the middle-arm voltage is $0.258 V_{d c}$ for asymmetrical machines and $0.5 V_{d c}$ for symmetrical machines. Therefore, the number of employed FB-SMs in the middle arm is designed as $30 \%$ and $50 \%$ of the number of employed HB-SMs in either the upper or lower arms for asymmetrical and symmetrical machines, respectively.

\section{B. Arm Currents}

The machine currents $\left(i_{a}\right.$ and $i_{x}$ ) supplied by leg-1 are described by (6), where $I_{o}$ is the current magnitude and $\delta$ is the machine power-factor angle.

$$
\begin{gathered}
i_{a}=I_{o} \cos (\omega t-\delta) \\
i_{x}=I_{o} \cos (\omega t+\emptyset-\delta)
\end{gathered}
$$

The arm currents are defined in relation to the machine currents as:

$$
\begin{aligned}
i_{U 1} & =i_{\text {circ }}+i_{a} \\
i_{M 1} & =i_{\text {circ }} \\
i_{L 1} & =i_{\text {circ }}-i_{x}
\end{aligned}
$$

where $i_{\text {circ }}$ is the circulating current passing through the $\mathrm{dc}$ loops comprising the $\mathrm{dc}$ side and each converter leg. The circulating current is fundamentally formed by a dc component associated with the active power transfer between the converter and the dc side, in addition to a series of loworder harmonics due to the SM capacitor voltage fluctuations in attempt to keep the voltage balance between the dc side and the converter legs. It is worth mentioning that in a standard MMC, the circulating current experiences only even-order harmonics, where the odd-harmonics appear differentially in the capacitor voltage fluctuation of both the upper- and lowerarm SMs due to the out-of-phase modulation of both arms. Therefore, the influence of the odd-harmonics is cancelled in the circulating current. On the other side, the circulating current of the hybrid 9A-MMC experiences both even and odd harmonics, while their magnitudes depend on the modulation phase angle between both the upper and lower arms. Among these low-order harmonics, the second-order harmonic has the largest magnitude, and then the third-order harmonic with a lower magnitude. Due to its dominant effect, the second-order harmonic is suppressed through several approaches, while the effect of the remaining third-order harmonic on the circulating current can be fairly neglected without affecting the forthcoming analysis. Accordingly, the circulating current is assumed to be only the dc component, and is defined as one third of the dc input current, $i_{d c}$, as follows.

$$
i_{\text {circ }}=\frac{i_{d c}}{3}=\frac{M I_{o} \cos \delta}{2}
$$

\section{SM Capacitor Voltage}

Due to the asymmetric operational behavior of the hybrid 9A-MMC, the capacitive energy stored in the middle arm will have different alternation than that of both the upper and lower arms, which is eventually manifested in the corresponding SM capacitor voltage with different ripple profiles. With the modulation of (3) and (4), the capacitor current, $i_{C}$, for an upper-, middle-, and lower-arm SM is described as:

$$
\begin{gathered}
i_{C U 1}=\frac{1}{2}[1-M \cos (\omega t)] i_{U 1} \\
i_{C M 1}=\frac{1}{2} M \sqrt{2(1-\cos \emptyset)} \cos (\omega t+\alpha) i_{M 1} \\
i_{C L 1}=\frac{1}{2}[1+M \cos (\omega t+\emptyset)] i_{L 1}
\end{gathered}
$$

By integrating (9), the capacitor voltage fluctuation of SMs in the three arms is calculated as:

$$
\begin{aligned}
& \Delta v_{C U 1}=\frac{1}{C} \int_{0}^{t} i_{C U 1} d t \\
& =\frac{I_{o}}{4 \omega C}\left[\sqrt{4+\cos ^{2} \delta\left(M^{4}-4 M^{2}\right)} \sin (\omega t+\beta)\right. \\
& -M \sin (2 \omega t-\delta)] \\
& \Delta v_{C M 1}=\frac{1}{C} \int_{0}^{t} i_{C M 1} d t \\
& =\left[\frac{M^{2} I_{o} \cos \delta}{4 \omega C} \sqrt{2(1-\cos \emptyset)}\right] \sin (\omega t+\alpha) \\
& \Delta v_{C L 1}=\frac{1}{C} \int_{0}^{t} i_{C L 1} d t \\
& =\frac{I_{o}}{4 \omega C}\left[-\sqrt{4+\cos ^{2} \delta\left(M^{4}-4 M^{2}\right)} \sin (\omega t+\beta)\right. \\
& -M \sin (2(\omega t+\emptyset)-\delta)]
\end{aligned}
$$

where $\beta$ is given as:

$$
\beta=\tan ^{-1} \frac{2 \tan \delta}{M^{2}-2}
$$

\section{SM Capacitance Design}

From (10), the capacitor voltage ripple for both the upperand lower-arm SMs pulsate due to both the first- and secondfrequency harmonics. Whereas, the middle-arm SM has a capacitor voltage ripple pulsating at the fundamental frequency. Therefore, the middle-arm SM capacitance design is quite different compared to that of both the upper- and lower-arm SMs' capacitance, for the same voltage-ripple profile.

Figs. 4 and 5 investigate the response of capacitor voltage ripple with operating parameters variation, where the normalized SM capacitor voltage ripple is observed in 3-D relationships, for different-arm SMs. The influence of both load current and power factor variation on capacitor voltage ripple is shown in Fig. 4a for both the upper- and lower-arm SMs, while shown in Fig. $4 \mathrm{~b}$ for the middle-arm SMs. Although the voltage ripple is directly proportional to the load current, there is a remarkable disparity in the correspondent SM voltage ripple variation, where the increase of the middlearm SM voltage ripple due to the load current increase is 
normalized capacitor voltage ripple $\left(\% \Delta V_{c U / L} / V_{c}\right)$

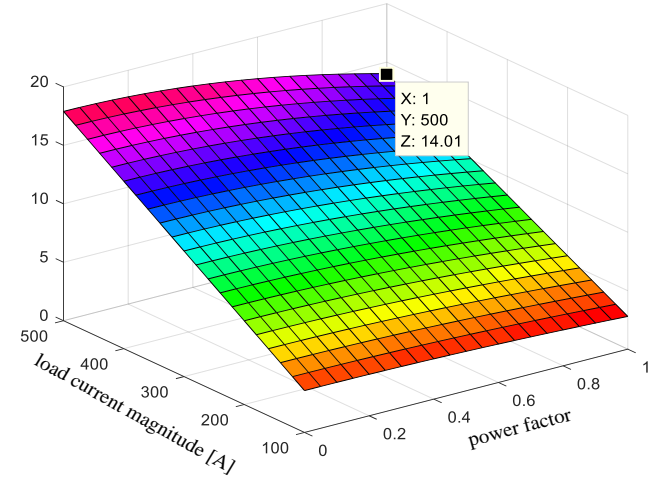

(a)

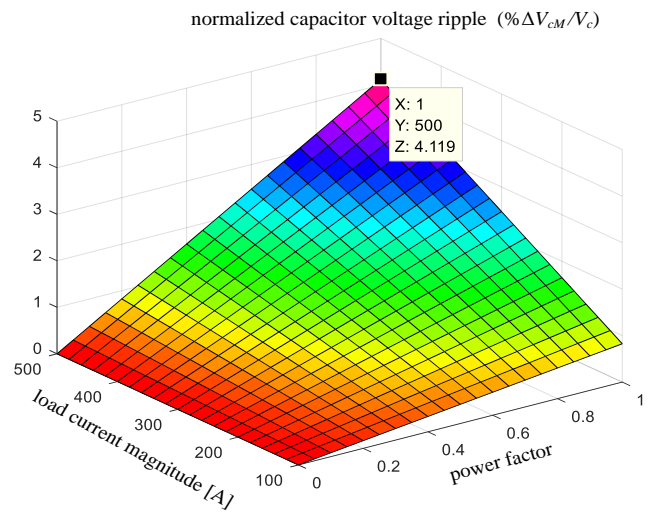

(b)

Fig. 4 Normalized peak-to-peak capacitor voltage ripple for various operating conditions of load current and power factor, for (a) upper- and lower-arm SMs and (b) middle-arm SM. $\left(M=1, f=50 \mathrm{~Hz}, C=5 \mathrm{mF}, \varnothing=30^{\circ}\right.$, and $\left.V_{c}=2 \mathrm{kV}\right)$

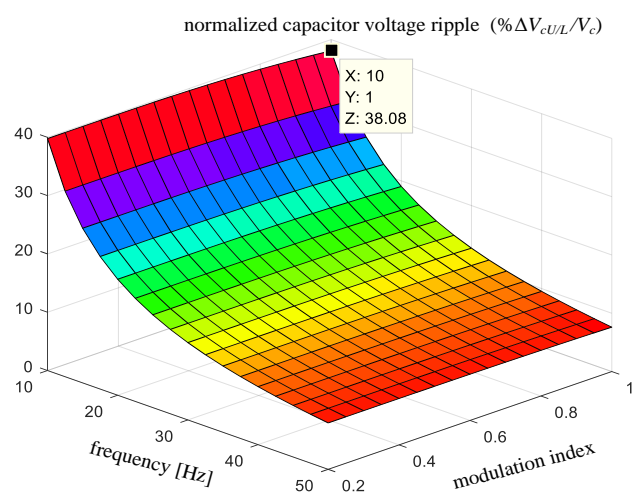

(a)

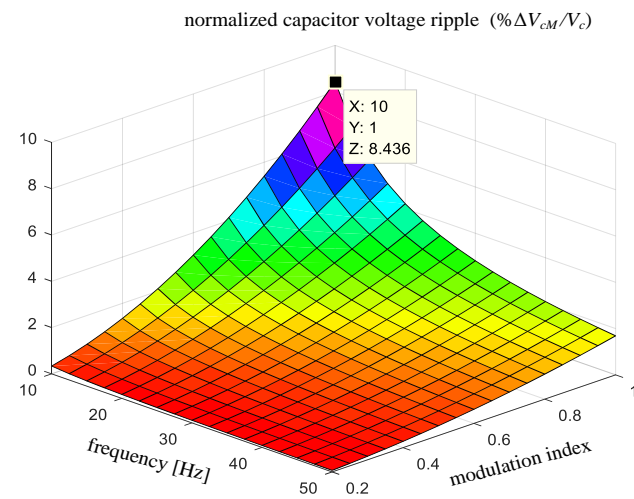

(b)

Fig. 5 Normalized peak-to-peak capacitor voltage ripple for various operating conditions of operating frequency and modulation index, for (a) upper- and lower-arm SMs and (b) middle-arm SM. $\left(I_{o}=250 \mathrm{~A}, \delta=35^{\circ}, C=5 \mathrm{mF}, \varnothing=30^{\circ}\right.$, and $\left.V_{c}=2 \mathrm{kV}\right)$

significantly lower than that of both the upper- and lower-arm SMs. In addition, while the middle-arm SM voltage ripple is in direct proportion to the power factor, both the upper- and lower-arm SM voltage ripple are inversely proportional to the power factor. To quantify the voltage ripple diversity, the maximum voltage ripple ratio between both the upper- and lower-arm SMs and the middle-arm SMs is recorded as 3.4.

In a similar way, Fig. 5 shows the voltage ripple profile in response to both operating frequency and modulation index variation. Fig. 5a shows that the voltage ripple of both upperand lower-arm SMs is slightly inversely proportional to the modulation index, but significantly inversely proportional to the operating frequency. On the other hand, the middle-arm SM voltage ripple, shown in Fig. 5b, is slightly increasing with either increased modulation index or operating frequency. The ratio between the maximum recorded voltage ripple in Fig. 5a to Fig. 5b is 4.5. It is worth mentioning that the results in both Figs. 4 and 5 assume the hybrid 9A-MMC is driving an asymmetrical machine, where $\varnothing$ is set to $30^{\circ}$. Unlike both the upper and lower arms, the middle-arm SM capacitor voltage ripple depends on the phase angle $\varnothing$, where it is almost doubled when the hybrid 9A-MMC drives a symmetrical six-phase machine, compared to an asymmetrical one. Nonetheless, the middle-arm SM capacitance can be reduced to quarter and half the upper- and lower-arm SM capacitance, for asymmetrical and symmetrical machines, respectively.

\section{CONTROL METHOD}

A phase disposition PWM-based modulator, with a switching frequency $f_{s w}$, is utilized for each leg of the hybrid 9A-MMC to command a varying number of SMs to be inserted at each time instant in the different arms. This is schematically illustrated in Fig. 6 for one leg of the hybrid 9AMMC. Both the upper- and lower-arm reference voltages, as given by (3), are utilized as input to the modulator which accordingly determines the necessary number of HB-SMs to be inserted in both the upper and lower arms, as denoted by $n_{U 1}$ and $n_{L 1}$, respectively. To ensure a zero voltage summation in the outer loop, the number of FB-SMs to be inserted in the middle arm is calculated as $n_{M 1}=N-n_{U 1}-$ $n_{L 1}$, where a limiter with a bandwidth of either $\pm 0.3 N$ or $\pm 0.5 \mathrm{~N}$ is utilized for the asymmetrical and symmetrical operation mode of the hybrid 9A-MMC, respectively. The positive sign of $n_{M 1}$ indicates operating the middle-arm FBSMs under positive voltage state (that is, positive SM output voltage), while the negative sign indicates a negative output voltage state. 


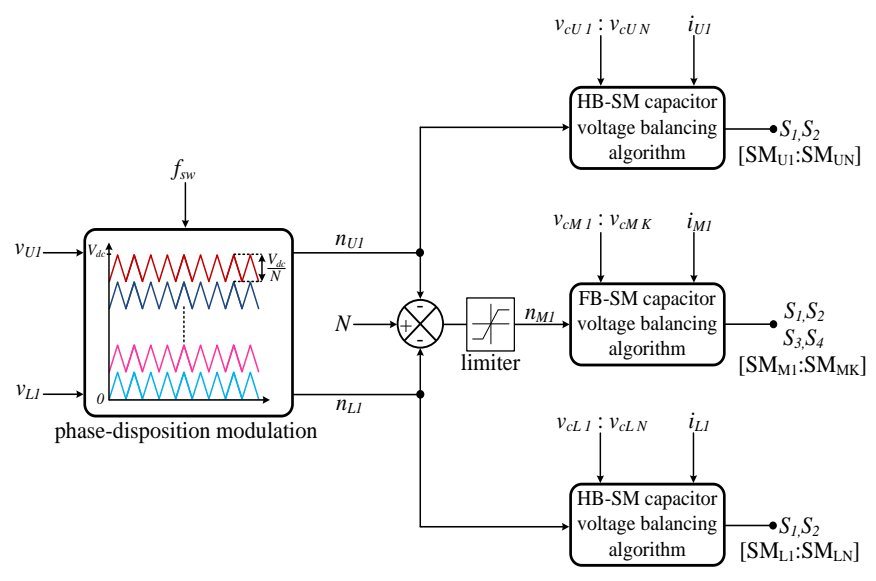

Fig. 6 A schematic diagram for the modulation and control of one leg of the hybrid $9 \mathrm{~A}-\mathrm{MMC}$.

A capacitor voltage balancing algorithm is applied to maintain all of the SM capacitors balanced around the nominal value, which is realized by a selection mechanism based on capacitor voltage measurements at each switching instance. This mechanism sorts the SM capacitor voltages and then decides which individual SM is inserted or bypassed, according to the arm current direction [27]. It should be noted that, although the middle-arm current is unidirectional, the FB-SMs can charge and discharge their capacitors by changing the arm-current polarity passing through the capacitors when inserted in the conduction path.

\section{VERIFICATION}

The performance of the proposed hybrid 9A-MMC has been examined using both simulation and experimentation, with the parameters listed in Table I.

\section{A. Verification using RL Load}

A 3.2 MW MATLAB/SIMULINK simulation model is used to verify the features of the proposed hybrid 9A-MMC while feeding a six-phase $R L$ load $(R=15 \Omega, L=30 \mathrm{mH})$, in comparison to the traditional 12A-MMC. The simulation results are shown in Figs. 7 and 8 for an asymmetrical modulation $\left(\varnothing=30^{\circ}\right)$ of both the 12A-MMC and hybrid 9AMMC, respectively. Common to both topologies, the number of HB-SMs in both the upper and lower arms is 10. That is, the number of FB-SMs in the middle arm of the hybrid 9AMMC is 3. In both Figs. 7 and 8, the six-phase line voltages and load currents show high quality sinusoidal waveform with $30^{\circ}$ phase shift between the $a b c$ and $x y z$ three-phase sets. Both the upper- and lower-arm voltages, of both topologies, step from 0 to $10 \mathrm{kV}$ through eleven voltage levels. Whereas, the middle-arm voltage of the hybrid 9A-MMC is bidirectional and steps with $\pm 3 \mathrm{kV}$ amplitude.

Using a parallel-resonant filter, the second-order harmonic is eliminated in the circulating current of both topologies [23]. That is, both the upper- and lower-arm currents of the $12 \mathrm{~A}$ MMC show a good out-of-phase sinusoidal profile, where the circulating current is a dc component. Similarly, both the upper- and lower-arm currents of the hybrid 9A-MMC are showing good sinusoidal profile with a doubled value
TABLE I

PARAMETERS FOR SIMULATION AND EXPERIMENT

\begin{tabular}{lcc}
\hline \hline Hybrid 9A-MMC parameters & Simulation & Experiment \\
\hline \hline $\begin{array}{l}\text { Number of HB-SMs in both } \\
\text { upper and lower arms }(N)\end{array}$ & 10 & 3 \\
\hline \hline Rated active power & $3.2 \mathrm{MW}$ & $4 \mathrm{~kW}$ \\
\hline \hline Input dc voltage $\left(V_{d c}\right)$ & $10 \mathrm{kV}$ & $300 \mathrm{~V}$ \\
\hline \hline Line voltage & $6 \mathrm{kV}$ & $180 \mathrm{~V}$ \\
\hline \hline Output current & $175 \mathrm{~A}$ & $6.5 \mathrm{~A}$ \\
\hline \hline Nominal SM capacitor voltage $\left(V_{c}\right)$ & $1 \mathrm{kV}$ & $100 \mathrm{~V}$ \\
\hline \hline Fundamental output frequency $\left(f_{o}\right)$ & $50 \mathrm{~Hz}$ & $50 \mathrm{~Hz}$ \\
\hline \hline PWM switching frequency $\left(f_{s w}\right)$ & $2 \mathrm{kHz}$ & $2 \mathrm{kHz}$ \\
\hline \hline Arm inductance $\left(L_{a r m}\right)$ & $5 \mathrm{mH}$ & $2.8 \mathrm{mH}$ \\
\hline \hline SM capacitance $(C)$ & $6 \mathrm{mF}$ & $2.2 \mathrm{mF}$ \\
\hline \hline
\end{tabular}

compared to that of the 12A-MMC, while the middle-arm current (equivalent to the circulating current) exhibits a dc component with slight fluctuation due to the influence of the uncompensated third-order harmonic which clearly appears in the dc input current with a tripled value.

Investigating the SM capacitor voltage, both the upper- and lower-arm SMs, of both topologies, pulsate due to both the first- and second-frequency components, with a $\pm 5 \%$ voltage ripple. To maintain such an equal band of voltage ripple, the $\mathrm{SM}$ capacitance is set to $3 \mathrm{mF}$ and $6 \mathrm{mF}$ for the 12A-MMC and the hybrid 9A-MMC, respectively. The middle-arm SM capacitor voltage of the hybrid 9A-MMC pulsates with the fundamental frequency at $\pm 1.4 \%$ using $6 \mathrm{mF}$ SM capacitance as well. That is, to achieve the same $\pm 5 \%$ voltage ripple profile across the different-arm SM capacitors, the middle-arm SM capacitance can be reduced to $1.3 \mathrm{mF}$.

\section{B. Verification using Six-Phase Machine}

The performance of the hybrid 9A-MMC is examined when driving a symmetrical six-phase machine, in an open-loop scheme, through both simulation and experimentation at the same operating conditions. That is, a scaled-down laboratory prototype is built to drive a symmetrical six-phase machine constructed by rewinding the stator of an existing three-phase induction machine with two identical three-phase single layer windings shifted in space by $60^{\circ}$. The constructed six-phase machine has half the number of turns per coil and same conductor cross sectional area, compared to the three-phase machine, to maintain the same copper volume. The threephase machine is rated at $4 \mathrm{~kW}, 415 \mathrm{~V}$ (line-to-line), $50 \mathrm{~Hz}$, $7.5 \mathrm{~A}, 1450 \mathrm{RPM}$ with two pole pairs. After rewinding, the rated voltage is halved, while other rated values are maintained. The number of HB-SMs in each of the upper and lower arms is 3, while the number of FB-SMs in the middle arms is 2. The control algorithm is implemented using TMS320F28335 Texas Instruments DSPs.

Both simulation and experimental results are presented in Figs. 9 and 10, respectively, at the same scale to allow one-toone comparison. In both figures, two line voltages of each three-phase set are shown to traverse with seven voltage levels, while the machine currents $i_{a}$ and $i_{x}$ are sinusoidal. Both the upper- and lower-arm voltages step between 0 and $300 \mathrm{~V}$, while the middle-arm voltage is bidirectional, alternating with $\pm 200 \mathrm{~V}$. The upper- and lower-arm currents 

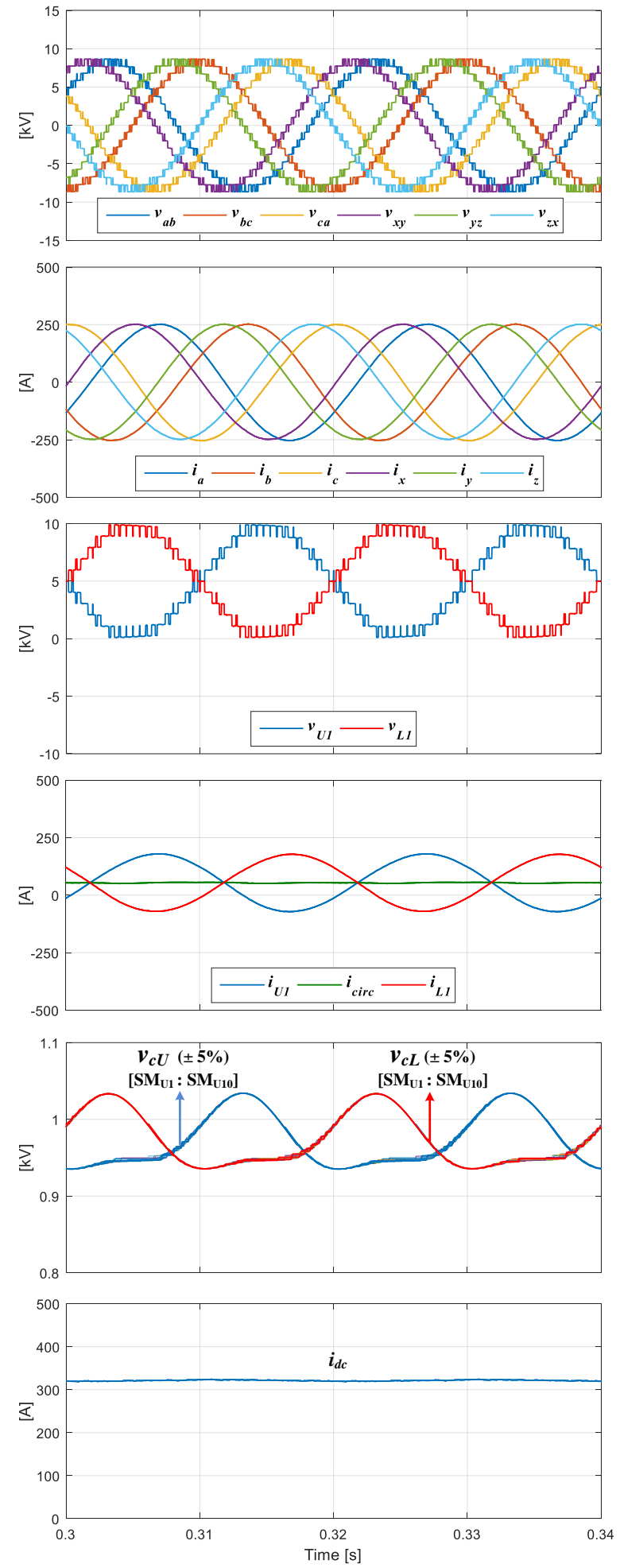

Fig. 7 Simulation results of the 12A-MMC while supplying an asymmetrical six-phase $R L$ load.

are showing a sinusoidal profile, however, distorted with loworder harmonics since the circulating current has not been controlled to suppress its inherited harmonics. Therefore, both the second- and third-order harmonics are simultaneously affecting the arm-current waveforms, as clearly appear in the fluctuation of the middle-arm current, with $23 \%$ and $8 \%$,
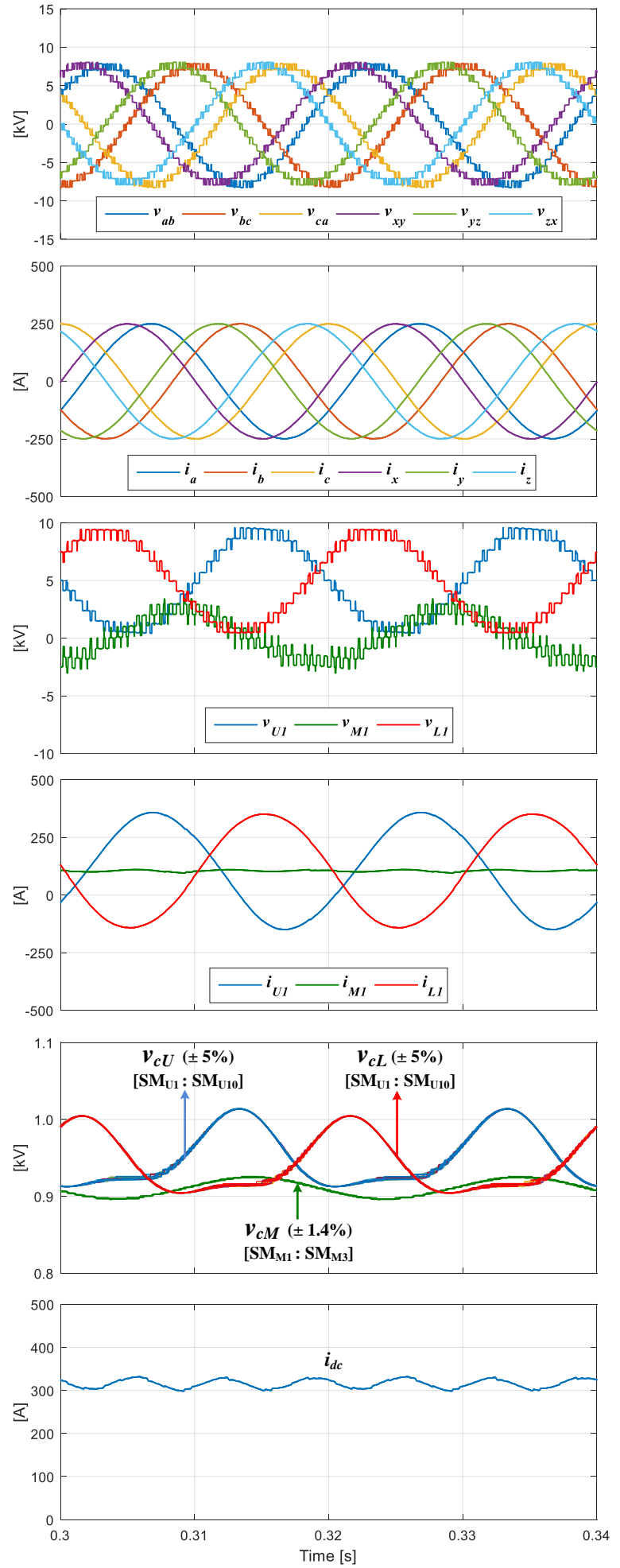

Fig. 8 Simulation results of the hybrid 9A-MMC while supplying an asymmetrical six-phase $R L$ load.

respectively. These harmonics appear further enlarged in the supply current waveform since their instantaneous value is tripled. The capacitor voltage of both the upper- and lowerarm SMs have $\pm 3 \%$ voltage ripple, while the middle-arm SM capacitor has $\pm 0.7 \%$ voltage ripple, where the capacitance of all SMs is $2.2 \mathrm{mF}$. 

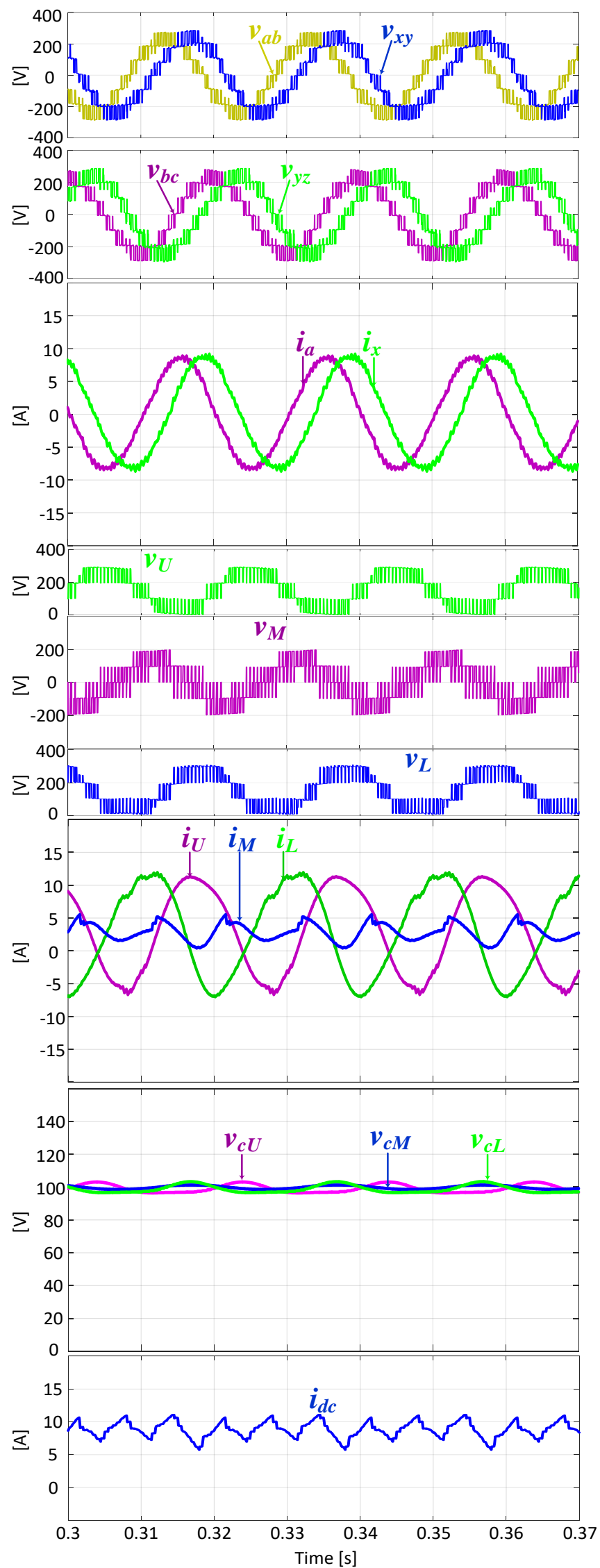

Fig. 9 Simulation results of the hybrid 9A-MMC while supplying a symmetrical six-phase machine.

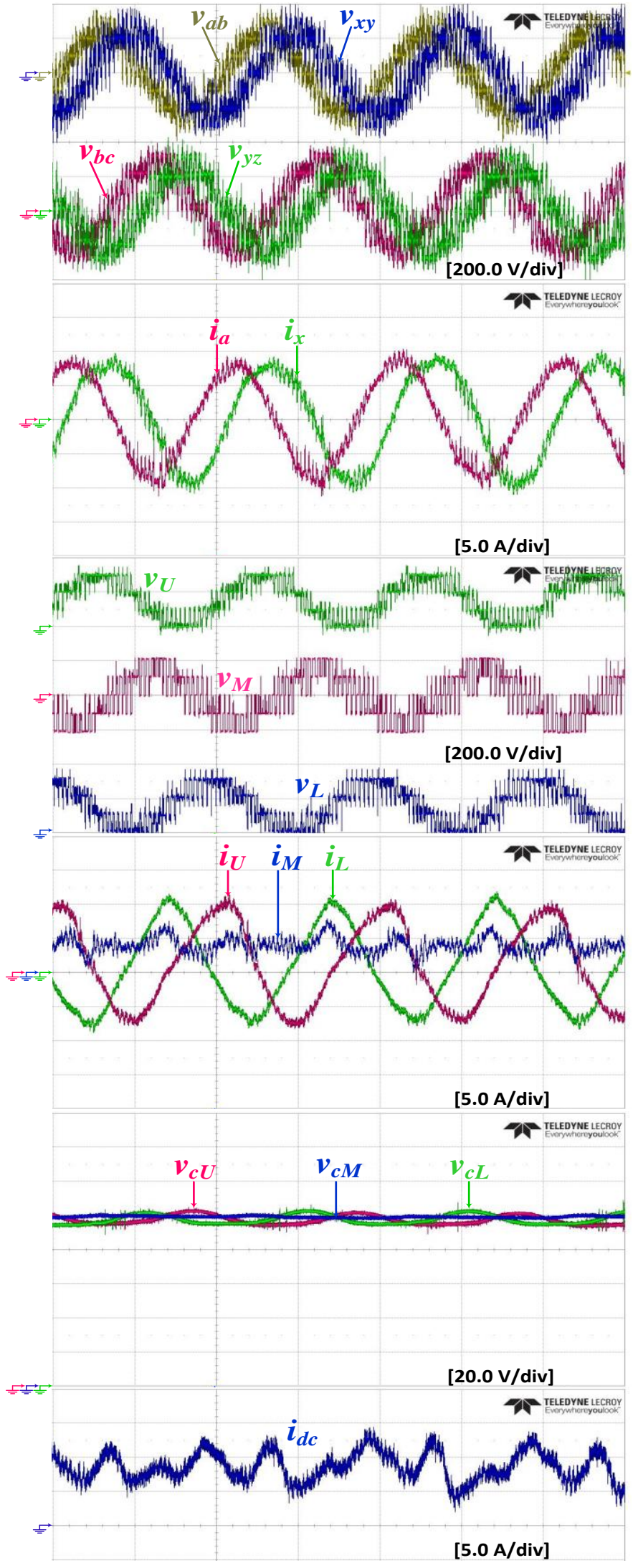

Fig. 10 Experimental results of the hybrid 9A-MMC while supplying a symmetrical six-phase machine (time scale: $10 \mathrm{~ms} / \mathrm{div}$ ). 
TABLE II

Quantitative Comparison between MMC-Based Six-Phase Machine Drive Topologies at Same DC-LinK Voltage

\begin{tabular}{|c|c|c|c|c|}
\hline & \multirow[t]{2}{*}{ 12A-MMC } & \multirow[t]{2}{*}{ 9A-MMC } & \multicolumn{2}{|c|}{ "Hybrid 9A-MMC } \\
\hline & & & $\emptyset=30^{\circ}$ & $\emptyset=60^{\circ}$ \\
\hline DC link voltage & $V_{d c}$ & $V_{d c}$ & \multicolumn{2}{|c|}{$V_{d c}$} \\
\hline Maximum AC voltage & $1 / 2 V_{d c}$ & $1 / 3 V_{d c}$ & \multicolumn{2}{|c|}{$1 / 2 V_{d c}$} \\
\hline Number of SMs & $12 \mathrm{~N} \mathrm{HB}-\mathrm{SMs}$ & 9N HB-SMs & $6 \mathrm{~N}$ HB-SMs and $0.9 \mathrm{~N}$ FB-SMs & $6 \mathrm{~N} \mathrm{HB}-\mathrm{SMs}$ and $1.5 \mathrm{~N} \mathrm{FB-SMs}$ \\
\hline Number of IGBTs & $24 \mathrm{~N}$ & $18 \mathrm{~N}$ & $15.6 \mathrm{~N}$ & $18 \mathrm{~N}$ \\
\hline Number of arm inductors & 12 & 6 & \multicolumn{2}{|c|}{6} \\
\hline Number of SM capacitors & $12 \mathrm{~N}$ & $9 \mathrm{~N}$ & $6.9 \mathrm{~N}$ & $7.5 \mathrm{~N}$ \\
\hline
\end{tabular}

TABLE III

Rating and Parameters Assessment of MMC-Based Six-Phase Machine Drive Topologies at Same PoWer LeVel

\begin{tabular}{|c|c|c|c|c|}
\hline & \multirow[t]{2}{*}{ 12A-MMC } & \multirow[t]{2}{*}{ 9A-MMC } & \multicolumn{2}{|c|}{ Hybrid 9A-MMC } \\
\hline & & & $\emptyset=30^{\circ}$ & $\emptyset=60^{\circ}$ \\
\hline DC link voltage & $V_{d c}$ & $3 V_{d c} / 2$ & \multicolumn{2}{|c|}{$V_{d c}$} \\
\hline IGBT rated voltage & $V_{d c} / N$ & $V_{d c} / N$ & \multicolumn{2}{|c|}{$V_{d c} / N$} \\
\hline IGBT rated current & $1 / 6 I_{d c}+1 / 2 I_{o}$ & $\begin{array}{l}\frac{2}{9} I_{d c}+2 I_{o} \text { for upper-arm IGBTs, } \\
\frac{2}{9} I_{d c}+I_{o} \text { for middle-arm IGBTs, and } \\
\frac{2}{9} I_{d c}+0.5 I_{o} \text { for lower-arm IGBTs }\end{array}$ & \multicolumn{2}{|c|}{$\begin{array}{l}1 / 3 I_{d c}+I_{o} \text { for upper- and lower-arm IGBTs } \\
\text { and } 1 / 3 I_{d c} \text { for middle-arm IGBTs }\end{array}$} \\
\hline Combined power rating & $12 V_{d c} I_{o}+4 V_{d c} I_{d c}$ & $21 V_{d c} I_{o}+4 V_{d c} I_{d c}$ & $12 V_{d c} I_{o}+5.2 V_{d c} I_{d c}$ & $12 V_{d c} I_{o}+6 V_{d c} I_{d c}$ \\
\hline \multirow{2}{*}{ SM capacitance } & \multirow{2}{*}{$C$} & \multirow{2}{*}{$\begin{array}{c}4 C \text { for upper-arm SMs, } \\
2 C \text { for middle-arm SMs, and } \\
C \text { for middle-arm SMs } \\
\end{array}$} & \multicolumn{2}{|c|}{$2 C$ for upper- and lower-arm SMs } \\
\hline & & & $0.5 C$ for middle-arm SMs & $C$ for middle-arm SMs \\
\hline Total capacitive stored energy & $12 N\left[1 / 2 C\left(V_{d c} / N\right)^{2}\right]$ & $21 N\left[1 / 2 C\left(V_{d c} / N\right)^{2}\right]$ & $12.45 N\left[1 / 2 C\left(V_{d c} / N\right)^{2}\right]$ & $12.75 N\left[1 / 2 C\left(V_{d c} / N\right)^{2}\right]$ \\
\hline Arm Inductance & 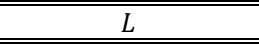 & 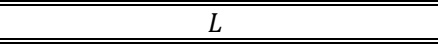 & \multicolumn{2}{|c|}{$L$} \\
\hline Total reactive elements & $12 N C+12 L$ & $21 N C+6 L$ & $12.45 N C+6 L$ & $13.5 N C+6 L$ \\
\hline
\end{tabular}

\section{Assessment of the PROposed Hybrid 9A-MMC}

Promoted by the inclusion of FB-SMs, the hybrid 9A-MMC achieves the same voltage utilization as the standard 12AMMC, however with a reduced component count. Table II assesses the number of components employed by the hybrid 9A-MMC, for both asymmetrical and symmetrical operation, in comparison to both the standard 12A-MMC and 9A-MMC, while Table III assesses the IGBTs rating and reactive element design at the same power level and SM capacitor voltage ripple. While the IGBT rated voltage is identical for different SMs in both the 12A-MMC and the hybrid 9A-MMC, the rated current is doubled for both the upper- and lower-arm IGBTs, and is reduced by $40 \%$ for the middle-arm IGBTs of the hybrid 9A-MMC, compared to the 12A-MMC.

In [9], the SM capacitor voltage ripple has been analyzed in detail for a standard MMC topology, and categorized into first- and second-frequency ripple components, where it was shown that the first-frequency component is the dominant component in the SM capacitor voltage ripple. Since both the upper- and lower-arm currents of the hybrid 9A-MMC topology are twice the arm currents of a standard MMC, the first-frequency ripple component of the hybrid 9A-MMC is twice that of a standard MMC. Therefore, the SM capacitance of both the upper- and lower-arm SMs are designed as twice as the SM capacitance of a standard MMC SMs, for the same voltage ripple. Whilst, the middle-arm SM capacitance is selected as quarter and as half the upper-/lower-arm SM capacitance, for the asymmetrical and symmetrical designs of the hybrid 9A-MMC, respectively.
Fig. 11 shows a graphical assessment of the hybrid 9AMMC in comparison to the 12A-MMC, where the latter's parameters are set as $1 \mathrm{pu}$, and are used as a reference for the former's parameters. While the number of arm inductors is reduced by $50 \%$, the number of SM capacitors is reduced by $42.5 \%$ and $37.5 \%$ for asymmetrical and symmetrical designs of the proposed topology, respectively. However, the sum of the total employed inductance and capacitance is almost the same for both the 12A-MMC and the hybrid 9A-MMC, while the total capacitive stored energy is slightly increased by $3.8 \%$ and $6.3 \%$ for the asymmetrical and symmetrical designs of the hybrid 9A-MMC, respectively. Also, the number of IGBTs is reduced by $35 \%$ and $25 \%$; nonetheless, the combined power rating of the IGBTs is increased by $8.6 \%$ and $14.3 \%$, where the values denote for the asymmetrical and symmetrical modes of the hybrid 9A-MMC, respectively.

To assess the size of the hybrid 9A-MMC, compared to the 12A-MMC, the $3.2 \mathrm{MW}$ system investigated in the simulation study is selected as the performance index. That is, the $5 \mathrm{SNG}$ 0450R170300 phase-leg IGBT module with $1.7 \mathrm{kV}, 450 \mathrm{~A}$ [28] is selected for both the upper- and lower-arm SMs of the hybrid 9A-MMC, while the 5SNG 0225R170300 phase-leg IGBT module with $1.7 \mathrm{kV}, 225 \mathrm{~A}$ [29] is selected for the middle-arm SMs of the hybrid 9A-MMC and for the 12AMMC's SMs as well, where both IGBT modules are from $\mathrm{ABB}$. Although the current rating is doubled, the size of both IGBT modules is the same, and is calculated as $0.1628 \mathrm{~L}$. To assess the SM capacitors size, according to the power 


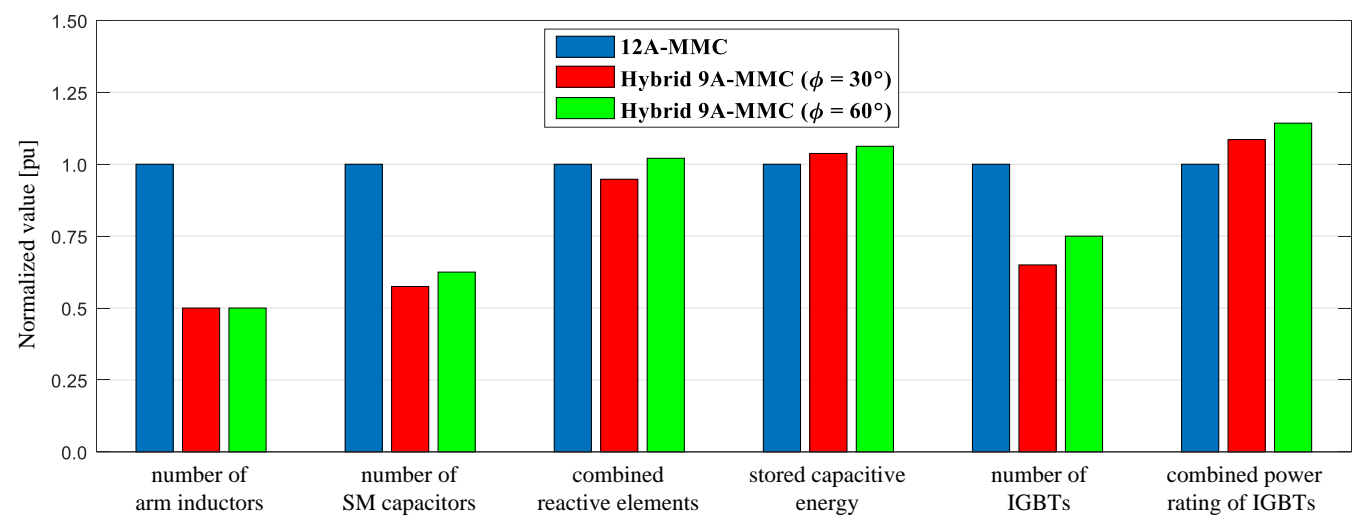

Fig. 11 Graphical assessment of the proposed hybrid 9A-MMC in comparison to the 12A-MMC.

capacitors from EPOCS [30], [31], the volume of $6 \mathrm{mF}, 3 \mathrm{mF}$, and $1.5 \mathrm{mF}$ capacitors are $19 \mathrm{~L}, 11.56 \mathrm{~L}$, and $2.88 \mathrm{~L}$, respectively, all with $1.1 \mathrm{kV}$. Accordingly, the total capacitance size of the 12A-MMC (incorporating $12 \mathrm{~N}$ capacitors each with $3 \mathrm{mF}$ ) is $1387.2 \mathrm{~L}$. Whereas, the total capacitance size of the hybrid 9A-MMC (incorporating $6 \mathrm{~N}$ capacitors each with $6 \mathrm{mF}$ in addition to either $0.9 \mathrm{~N}$ capacitors with $1.5 \mathrm{mF}$ or $1.5 \mathrm{~N}$ capacitors with $3 \mathrm{mF}$ ) is $1166 \mathrm{~L}$ and 1313.4 L, for asymmetrical and symmetrical hybrid9AMMCs, respectively. That is, the hybrid 9A-MMC achieves $16 \%$ and $6 \%$ size reduction for asymmetrical and symmetrical operation, respectively. It should be noted that this is only a comparison for the size of the main SM components (capacitors and IGBTs), rather than a comparison of the volume of real SM enclosures (in which there are more components). Nevertheless, an additional decrease in the whole system size is expected, due to the reduction in the number of gate-drive circuits and both voltage and current transducers.

To assess the efficiency of the hybrid 9A-MMC, the power loss calculation method in [32] is adopted, with the IGBTs parameters given in their datasheets. While the efficiency of the $12 \mathrm{~A}-\mathrm{MMC}$ is $97.9 \%$, the efficiency of the hybrid 9AMMC is $97.4 \%$ and $97.3 \%$ for the asymmetrical and symmetrical cases, respectively. Although these efficiencies are case specific, a general deduction can be drawn that the hybrid 9A-MMC's efficiency does not deviate significantly from that of the 12A-MMC.

The economic feasibility of the hybrid 9A-MMC is examined by performing a cost analysis for the main employed components. According to the mainstream suppliers in the electronics market, the hybrid 9A-MMC achieves $17 \%$ and $9 \%$ cost reduction when designed to drive an asymmetrical or symmetrical six-phase machine, respectively, as compared to the conventional 12A-MMC.

\section{CONCLUSION}

A hybrid 9A-MMC with a combination of HB- and FB-SMs has been proposed in this paper, as an MV six-phase machine drive. Unlike the standard 9A-MMC with identical HB-SMs, the proposed topology achieves the same dc-link voltage utilization as a traditional 12A-MMC, however with a reduced component-count. This results in a reduction in the overall size and cost of the MMC-based six-phase drive system without any compromise neither in the amount of delivered power nor the efficiency. The operational features of the proposed topology have been theoretically analyzed in detail, and verified through both simulation and experimental examination. In addition, the characteristics of the proposed topology have been quantitatively assessed in comparison to both the standard 9A-MMC and 12A-MMC configurations.

Future research will be directed to applying suitable approaches for efficient operation of the hybrid 9A-MMC topology at low frequencies, for variable-speed drive applications.

\section{REFERENCES}

[1] R. D. Klug, N. Klaassen, "High Power Medium Voltage DrivesInnovations, Portfolio, Trends," 2005 European Conference on Power Electronics and Applications, 11-14 September 2005.

[2] S. Rizzo and N. Zargari, "Medium voltage drives: what does the future hold?," The $4^{\text {th }}$ International Power Electronics and Motion Control Conference, IPEMC 2004., Xi'an, pp. 82-89 Vol.1.

[3] S. Bernet, "Recent developments of high power converters for industry and traction applications," IEEE Trans. Power Electron., vol. 15, no. 6, pp. 1102-1117, Nov. 2000.

[4] S. Debnath, J. Qin, B. Bahrani, M. Saeedifard, and P. Barbosa, "Operation, control, and applications of the modular multilevel converter: A review," IEEE Trans. Power Electron., vol. 30, no. 1, pp. 37-53, Jan. 2015.

[5] A. Lesnicar and R. Marquardt, "An innovative modular multilevel converter topology suitable for a wide power range," in Proc. IEEE Power Tech. Conf., Bologna, Italy, Jun. 23-26, 2003, vol. 3.

[6] M. Hagiwara, I. Hasegawa, and H. Akagi, "Start-up and low-speed operation of an electric motor driven by a modular multilevel cascade inverter," IEEE Trans. Ind. Appl., vol. 49, no. 4, pp. 1556-1565, Jul./Aug. 2013.

[7] A. Antonopoulos, L. Angquist, S. Norrga, K. Ilves, L. Harnefors, H.-P. Nee, "Modular multilevel converter ac motor drives with constant torque from zero to nominal speed," IEEE Trans. Ind. Appl., vol. 50, no. 3, pp. 1982-1993, May/Jun. 2014.

[8] B. Li, S. Zhou, D. Xu, R. Yang, D. Xu, C. Buccella, and C. Cecati, "An improved circulating current injection method for modular multilevel converters in variable-speed drives" IEEE Trans. Ind. Electron., vol. 63, no. 11, pp. 7215-7225, Nov. 2016.

[9] M. S. Diab; A. M. Massoud; S. Ahmed; B. W. Williams, "A Dual Modular Multilevel Converter with High-Frequency Magnetic Links Between Sub-Modules for MV Open-End Stator Winding Machine Drives" IEEE Trans. Power Electron., vol. 33, no. 6, pp. 5142-5159, June 2018.

[10] E. Levi, "Advances in converter control and innovative exploitation of additional degrees of freedom for multiphase machines," IEEE Trans. Ind. Electron., vol. 63, no. 1, pp. 433-448, Jan. 2016.

[11] F. Barrero and M. J. Duran, "Recent advances in the design, modeling and control of multiphase machines-Part 1," IEEE Trans. Ind. Electron., vol. 63, no. 1, pp. 449-458, Jan. 2016. 
[12] M. J. Duran and F. Barrero, "Recent advances in the design, modeling and control of multiphase machines-Part 2," IEEE Trans. Ind. Electron., vol. 63, no. 1, pp. 459-468, Jan. 2016.

[13] E. Levi, F. Barrero and M. J. Duran, "Multiphase machines and drives Revisited," in IEEE Transactions on Industrial Electronics, vol. 63, no. 1, pp. 429-432, Jan. 2016.

[14] A. Pantea, A. Yazidi, F. Betin, M. Taherzadeh, S. Carrière, H. Henao, and G. Capolino, "Six-phase induction machine model for electrical fault simulation using circuit-oriented method" IEEE Trans. Ind. Electron., vol. 63, no. 1, pp. 494-503, Jan. 2016

[15] I. Gonzalez-Prieto, M. J. Duran, J. J. Aciego, C. Martin and F. Barrero, "Model Predictive Control of Six-Phase Induction Motor Drives Using Virtual Voltage Vectors," in IEEE Transactions on Industrial Electronics, vol. 65 , no. 1, pp. 27-37, Jan. 2018.

[16] A. C. N. Maia, C. B. Jacobina, N. B. de Freitas and I. R. F. M. P. da Silva, "Open-End Multilevel Six-Phase Machine Drive System With Five ThreeLeg Converters," IEEE Trans. Ind. Appl., vol. 53, no. 3, pp. 2271-2281, MayJune 2017.

[17] W. N. W. A. Munim, M. J. Duran, H. S. Che, M. Bermúdez, I. GonzálezPrieto and N. A. Rahim, "A Unified Analysis of the Fault Tolerance Capability in Six-Phase Induction Motor Drives," IEEE Trans. Power Electron., vol. 32, no. 10, pp. 7824-7836, Oct. 2017.

[18] E. Ariff, O. Dordevic, and M. Jones, "A space vector PWM technique for a three-level symmetrical six phase drive," IEEE Trans. Ind. Electron., vol. 64, no. 11, pp. 8396-8405, Nov. 2017.

[19] M. S. Diab, A. A. Elserougi, A. S. Abdel-Khalik, A. M. Massoud and S. Ahmed, "A Nine-Switch-Converter-Based Integrated Motor Drive and Battery Charger System for EVs Using Symmetrical Six-Phase Machines," IEEE Trans. Ind. Electron., vol. 63, no. 9, pp. 5326-5335, Sept. 2016.

[20] M. I. Daoud, A. Massoud, A. Abdel-Khalik and S. Ahmed, "An asymmetrical six-phase induction machine-based flywheel energy storage system using modular multilevel converters," 2016 19th International Conference on Electrical Machines and Systems (ICEMS), Chiba, 2016, pp. 1-6.

[21] M. S. Diab, B. W. Williams, D. Holliday, A. M. Massoud and S. Ahmed, "A modular multilevel converter with isolated energy-balancing modules for MV drives incorporating symmetrical six-phase machines," 2017 IEEE Energy Conversion Congress and Exposition (ECCE), Cincinnati, OH, USA, 2017, pp. 2715-2722.

[22] A. A. Elserougi, A. S. Abdel-Khalik, A. M. Massoud and S. Ahmed, "A ninearm modular multilevel converter (9A-MMC) for six-phase medium voltage motor drives" Industrial Electronics Society, IECON 2015-41st Annual Conference of the IEEE, vol., no., pp.1735-1740, 9-12 Nov. 2015.

[23] A. A. Elserougi, A. S. Abdel-Khalik, A. M. Massoud and S. Ahmed, "An asymmetrical six-phase induction motor drive based on nine-arm Modular Multilevel Converter (9AMMC) with circulating current suppression," 2015 4th International Conference on Electric Power and Energy Conversion Systems (EPECS), Sharjah, 2015, pp. 1-6.

[24] M. S. Diab, G. P. Adam, B. W. Williams, A. M. Massoud and S. Ahmed, "Quasi two-level PWM operation of a nine-arm modular multilevel converter for six-phase medium-voltage motor drives," 2018 IEEE Applied Power Electronics Conference and Exposition (APEC), San Antonio, TX, 2018, pp. 1641-1648.

[25] R. Zeng, L. Xu, L. Yao and B. W. Williams, "Design and Operation of a Hybrid Modular Multilevel Converter," in IEEE Trans. Power Electron., vol. 30, no. 3, pp. 1137-1146, March 2015.

[26] T. Kominami and Y. Fujimoto, "A novel nine-switch inverter for independent control of two three-phase loads," in Proc. IEEE Ind. Appl. Soc. Annu. Conf. (IAS), 2007, pp. 2346-2350.

[27] A. Antonopoulos, L. Angquist, and H.-P. Nee, "On dynamics and voltage control of the modular multilevel converter," in Proc. 13th EPE, 2009, pp. 110 .

[28] $A B B$ LoPak 5SNG 0450R170300, [online] Available: https://library.e.abb.com/public/a526a0fcfab646a19418fd64b88d1b00/5SNG $\% 200450$ R $170300 \% 205$ SYA $\% 20145101 \% 20201705 \% 20$ preliminary.pdf.

[29] $A B B$ LoPak 5SNG 0225R170300, [online] Available: https://library.e.abb.com/public/a40ce97a08574633b387b60bd3a3431d/5SN G\%200225R170300\%205SYA\%20145300\%20201705\%20preliminary.pdf.

[30] EPOCS Product Brief 2009. Power Capacitors, (2009), [online] Available:http://www.rollay.com.cn/ImgUpload/Articleimage/201007017405 22.pdf.

[31] EPOCS Product Brief 2016. Power Capacitors, (2016), [online] Available: https://en.tdk.eu/inf/20/50/ds/B2562_.pdf.

[32] D. Graovac and M. Pürschel, "IGBT power losses calculation using the datasheet parameters," [Online]. Available: http://applicationnotes.digchip.com/070/70-41484.pdf.

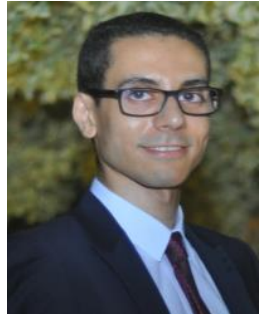

Mohamed S. Diab (S'09) received the B.Sc. (First Class Hons.) and M.Sc. degrees in electrical engineering from Alexandria University, Alexandria, Egypt, in 2012, and 2015, respectively. He is currently working toward the Ph.D. degree in electrical engineering at the University of Strathclyde, Glasgow, U.K. He was in the Department of Electrical Engineering, Alexandria University, where he was appointed as a Demonstrator in 2012 and as an Assistant Lecturer in 2015. He was with Spiretronic LLC, Alexandria branch, Egypt, as a Research Engineer from 2013 to 2015. His main research interests include medium-voltage applications, high-power electronic converters, renewable energy conversion systems, and electric drives.

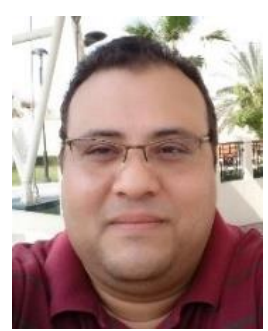

Ahmed A. Elserougi (SM'13) was born in Alexandria, Egypt, in September 1982. He received the B.Sc., M.Sc., and Ph.D. degrees in electrical engineering from the Faculty of Engineering, Alexandria University, Egypt, in 2004, 2006, and 2011, respectively. He is currently an Associate Professor in the Electrical Engineering Department, Faculty of Engineering, Alexandria University. His research interests include power quality, HVDC and FACTS, renewable energy, electric power utility, and pulsed power applications.

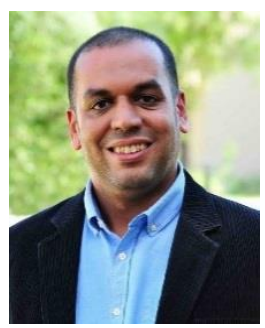

Ahmed M. Massoud (SM'11) received the B.Sc. (First Class Hons.) and M.Sc. degrees in electrical engineering from Alexandria University, Alexandria, Egypt, in 1997 and 2000, respectively, and the Ph.D. degree in electrical engineering from Heriot-Watt University, Edinburgh, U.K., in 2004. $\mathrm{He}$ is currently an Associate Professor at the Department of Electrical Engineering, College of Engineering, Qatar University. His research interests include power electronics, energy conversion, renewable energy and power quality. He holds five U.S. patents. He published more than 100 journal papers in the fields of power electronics, energy conversion, and power quality.

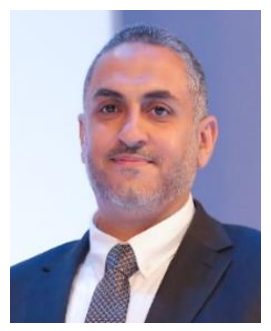

Shehab Ahmed (SM'12) received the B.Sc. degree from Alexandria University, Alexandria, Egypt, in 1999, and the M.Sc. and Ph.D. degrees from the Department of Electrical and Computer Engineering, Texas A\&M University, College Station, TX, USA, in 2000 and 2007, respectively, all in electrical engineering. He was with Schlumberger Technology Corporation, Houston, TX, USA, from 2001 to 2007, developing downhole mechatronic systems for oilfield service products. He was with Texas A\&M University at Qatar, Doha, Qatar, from 2007 to 2018 (currently on leave). He is currently a Professor of Electrical Engineering with the CEMSE division at King Abdullah University of Science and Technology, Saudi Arabia. His research interests include mechatronics, solid-state power conversion, electric machines, and drives.

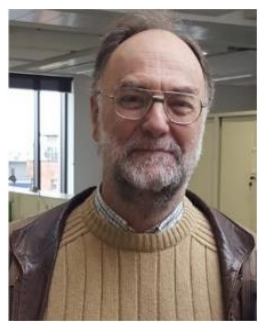

Barry W. Williams received the M.Eng.Sc. degree from the University of Adelaide, Adelaide, S.A., Australia, in 1978, and the Ph.D. degree from Cambridge University, Cambridge, U.K., in 1980, both in electrical engineering. After seven years as a Lecturer with Imperial College, University of London, London, U.K., he was appointed to a Chair of the Electrical Engineering, Heriot-Watt University, Edinburgh, U.K., in 1986. He is currently a Professor with the University of Strathclyde, Glasgow, U.K. His teaching covers power electronics (in which he has a free internet text) and drive systems. His research interests include power semiconductor modeling and protection, converter topologies, soft-switching techniques, and application of ASICs and microprocessors to industrial electronics. 